\title{
Mechanism of honey bacteriostatic action against MRSA and VRE involves hydroxyl radicals generated from honey's hydrogen peroxide
}

\author{
Katrina Brudzynski ${ }^{1,2}$ and Robert Lannigan ${ }^{3}$ \\ 1 API-Medicals, Brock University, St. Catharines, ON, Canada \\ ${ }^{2}$ Department of Biological Sciences, Brock University, St. Catharines, ON, Canada \\ ${ }^{3}$ Department of Clinical Microbiology, London Health Sciences Centre, London, ON, Canada
}

\section{Edited by:}

Mirian A. F. Hayashi, Universidade

Federal de São Paulo, Brazil

\section{Reviewed by:}

Atte Von Wright, University of Eastern

Finland, Finland

Charles Knapp, University of

Strathclyde, UK

\section{*Correspondence:}

Katrina Brudzynski, Department of

Biological Sciences, Brock University,

500 Glenridge Avenue, St. Catharines,

ON, Canada L2S $3 A 1$

e-mail: beebio@sympatico.ca
It has been recently reported that honey hydrogen peroxide in conjunction with unknown honey components produced cytotoxic effects resulting in bacterial growth inhibition and DNA degradation. The objective of this study was twofold: (a) to investigate whether the coupling chemistry involving hydrogen peroxide is responsible for a generation of hydroxyl radicals and (b) whether $\bullet \mathrm{OH}$ generation affects growth of multi-drug resistant clinical isolates. The susceptibility of five different strains of methicillin-resistant Staphylococcus aureus (MRSA) and four strains of vancomycin-resistant Enterococcus faecium (VRE) isolates from infected wounds to several honeys was evaluated using broth microdilution assay. Isolates were identified to genus and species and their susceptibility to antibiotics was confirmed using an automated system $\left(\operatorname{Vitek}^{\circledR}\right.$, Biomérieux $\left.{ }^{\circledR}\right)$. The presence of the $\operatorname{mec}(\mathrm{A})$ gene, nuc gene and $\operatorname{van}(\mathrm{A})$ and $(\mathrm{B})$ genes were confirmed by polymerase chain reaction. Results showed that no clinical isolate was resistant to selected active honeys. The median difference in honeys MICs against these strains ranged between 12.5 and $6.25 \% \mathrm{v} / \mathrm{v}$ and was not different from the MIC against standard Escherichia coli and Bacillus subtilis. Generation of $\bullet \mathrm{OH}$ during bacteria incubation with honeys was analyzed using $3^{\prime}$-(p-aminophenyl) fluorescein (APF) as the $\bullet{ }^{\bullet} \mathrm{OH}$ trap. The ${ }^{\bullet} \mathrm{OH}$ participation in growth inhibition was monitored directly by including APF in broth microdilution assay. The growth of MRSA and VRE was inhibited by $\bullet \mathrm{OH}$ generation in a dose-dependent manner. Exposure of MRSA and VRE to honeys supplemented with $\mathrm{Cu}(\mathrm{II})$ augmented production of $\bullet \mathrm{OH}$ by 30 -fold and increased honey bacteriostatic potency from $\mathrm{MIC}_{90} 6.25$ to $\mathrm{MIC}_{90}<0.78 \%$ $\mathrm{v} / \mathrm{v}$. Pretreatment of honeys with catalase prior to their supplementation with $\mathrm{Cu}$ ions fully restored bacterial growth indicating that hydroxyl radicals were produced from $\mathrm{H}_{2} \mathrm{O}_{2}$ via the Fenton-type reaction. In conclusion, we have demonstrated for the first time that bacteriostatic effect of honeys on MRSA and VRE was dose-dependently related to generation of $\bullet \mathrm{OH}$ from honey $\mathrm{H}_{2} \mathrm{O}_{2}$.

Keywords: hydroxyl radicals, $\mathrm{H}_{2} \mathrm{O}_{2}, 3^{\prime}$-(p-aminophenyl) fluorescein, growth inhibition, MRSA, VRE, mechanism of honey antibacterial activity

\section{INTRODUCTION}

Honey has well established function as an effective antibacterial agent with a broad spectrum of activity against Gram-positive and Gram-negative bacteria (for review, Lusby et al., 2002; Irish et al., 2011). Despite a progress in identification of compounds that are involved in growth inhibitory and bactericidal actions of honey, the mechanism underlying these activities remained unknown. A functional relationship between hydrogen peroxide produced in honey and antibacterial activity strongly pointed to $\mathrm{H}_{2} \mathrm{O}_{2}$ as the main contributor to this activity (White et al., 1963; Bang et al., 2003; Brudzynski, 2006). However, recent new findings question this view. Firstly, molecular $\mathrm{H}_{2} \mathrm{O}_{2}$ is relatively weak oxidant and it requires high concentrations to exert its cytotoxic effect (Rutala et al., 2008; Finnegan et al., 2010). Our data indicate that $\mathrm{H}_{2} \mathrm{O}_{2}$ content in honeys $(0.4-2.6 \mathrm{mM})$, is much below its biocidal levels. Yet, even at these low $\mathrm{H}_{2} \mathrm{O}_{2}$ concentrations, honeys effectively inhibited bacterial growth and caused DNA strand breaks (Brudzynski et al., 2011). Secondly, oxidative stress of endogenous $\mathrm{H}_{2} \mathrm{O}_{2}$ was clearly augmented by the action of unknown honey components (Brudzynski et al., 2011). Thirdly, in our accompanying paper, we provided the first evidence that honeys of high bacteriostatic activity $\left(\mathrm{MIC}_{90} 12.5-6.25 \% \mathrm{v} / \mathrm{v}\right)$ possessed significantly higher levels of phenolic compounds of higher radical scavenging activities than honey of the average bacteriostatic activity $\left(\mathrm{MIC}_{90} 25 \% \mathrm{v} / \mathrm{v}\right.$ ), thus suggesting the involvement of phenolics and $\mathrm{H}_{2} \mathrm{O}_{2}$ in bacterial growth inhibition (Brudzynski et al., 2012).

In our prior research, we have screened over 200 samples of Canadian honeys of different botanical origin for the antibacterial activity using broth microdilution assay (Brudzynski and Kim, 2011). Fifty percent of screened honeys showed MICs exceeding 
that of sugar solution. Among the group of "active" honeys, MICs of honeys originating from buckwheat differed consistently by four to 16 doubling concentrations from the MIC of sugar solution. Canadian buckwheat honeys characteristically contained higher amounts of hydrogen peroxide than other honeys (Brudzynski, 2006) and possessed higher than average content of polyphenols of high antioxidant activity as measured by the oxygen radical absorbent capacity (ORAC) method (Brudzynski and Miotto, 2011; Brudzynski et al., 2012). These results have converged to recognize that the coupling chemistry between $\mathrm{H}_{2} \mathrm{O}_{2}$ and polyphenols, rather than hydrogen peroxide alone, may exert oxidative effect causing bacterial growth arrest and DNA degradation (Brudzynski et al., 2011, 2012). High ORAC values of polyphenols are usually indicative of their efficient peroxyl radical scavenging abilities (Cao et al., 1997; Price et al., 2006). However, the same polyphenols could become powerful pro-oxidants when oxidized in the presence of oxygen from air. Such situation occurs during honey harvesting from the comb and during storage. Oxidized polyphenols further generate hydrogen peroxide and in the presence of transition metals such as $\mathrm{Cu}(\mathrm{I})$ or $\mathrm{Fe}(\mathrm{II})$ they drive the generation of hydroxyl radicals from $\mathrm{H}_{2} \mathrm{O}_{2}$ via the Fenton reaction (Puppo, 1992; Hanasaki et al., 1994; Cao et al., 1997; Sakihama et al., 2002).

Together, these facts brought about a new hypothesis that the oxidizing action of honey on bacterial cells may result from the generation of hydroxyl radicals from $\mathrm{H}_{2} \mathrm{O}_{2}$. Such coupling reaction has never been shown to be associated with honey function in spite of the fact that honey possesses all necessary substrates for the Fenton reaction; $\mathrm{H}_{2} \mathrm{O}_{2}$, polyphenols as well as transition metal ions (Bogdanov et al., 2007).

In contrast to $\mathrm{H}_{2} \mathrm{O}_{2},{ }^{\bullet} \mathrm{OH}$ radicals are powerful oxidants that can oxidize molecules in all cellular compartments in a nonspecific manner. ${ }^{\bullet} \mathrm{OH}$ cytotoxic effects have been shown for both prokaryotic and eukaryotic cells; bacteria, yeast, and human cells (Halliwell et al., 1985; Imlay and Linn, 1988; Perrone et al., 2008). For example, ${ }^{\bullet} \mathrm{OH}$ production from $\mathrm{H}_{2} \mathrm{O}_{2}$ by neutrophil granules is a first line of defense against bacteria during acute inflammation. Similarly, the $\mathrm{H}_{2} \mathrm{O}_{2}$-induced injury in Escherichia coli appears to be mediated by ${ }^{\bullet} \mathrm{OH}$ via Fenton reaction (Imlay and Linn, 1988; Imlay et al., 1988; Gutteridge et al., 1998). In the Fenton reaction in vivo, $\mathrm{H}_{2} \mathrm{O}_{2}$ is reduced to ${ }^{\circ} \mathrm{OH}$ radicals in the presence of ferrous (Fe II) or cuprous ( $\mathrm{Cu}$ II) ions, according to the equation $\mathrm{Me}^{n}+\mathrm{H}_{2} \mathrm{O}_{2}=\mathrm{Me}^{n+1}+{ }^{\bullet} \mathrm{OH}+\mathrm{OH}^{-}$. Importantly however, the efficiency of this reaction increases dramatically in the presence of polyphenols (Cao et al., 1997; Sakihama et al., 2002).

Therefore, it appeared likely to us that hydroxyl radicals generated from hydrogen peroxide in the Fenton reaction rather than $\mathrm{H}_{2} \mathrm{O}_{2}$ are main cytotoxic agents that underlie honey antibacterial activity. However, there was no direct experimental evidence that (a) honey can generate hydroxyl radicals from $\mathrm{H}_{2} \mathrm{O}_{2}$ and (b) that $\mathrm{H}_{2} \mathrm{O}_{2}$-derived ${ }^{\bullet} \mathrm{OHs}$ were responsible for bacterial growth and survival. In this study, we took advantage of $3^{\prime}$ - $(p$ aminophenyl) fluorescein (APF) as ${ }^{\bullet} \mathrm{OH}$ trap to investigate generation of hydroxyl radicals during exposure of bacterial cultures to honey.

Since $\mathrm{H}_{2} \mathrm{O}_{2}$ is a common component in honeys, a byproduct of glucose oxidation by honeybee glucose oxidase, we also explored a possibility that generation of hydroxyl radicals from honey hydrogen peroxide represents a general mechanism by which honey affects bacterial growth. In support of such notion are the following facts: (a) honeys from different botanical and geographical origins have been shown to possess antibacterial activity and (b) at least in some honeys, this activity has been shown to be directed against both antibiotic-sensitive as well as multi-resistant bacteria. This putative mechanism against antibiotic-resistant bacteria may function in honeys derived from Leptospermum spp., (manuka), Fagopyrum esculentum (buckwheat), Koompassia excelsa (tualang), and honeydew honeys (Willix et al., 1992; Cooper et al., 2000, 2002a,b; French et al., 2005; Brudzynski and Lannigan, 2008; Blair et al., 2009; Tan et al., 2009; Majtan et al., 2010).

To provide a better insight into the involvement of hydroxyl radicals on bacterial growth, we have chosen several clinical isolates of methicillin-resistant Staphylococcus aureus (MRSA) and vancomycin-resistant Enterococcus faecium (VRE) and monitored simultaneously their growth (by absorbance) and $\bullet{ }^{\bullet} \mathrm{OH}$ generation (by fluorescence) upon their incubation with active honeys. If the - $\mathrm{OH}$ generation proves to be implicated in the growth inhibition of standard bacteria (E. coli and Bacillus subtilis) as well as MRSA and VRE, then perhaps it could be concluded that honey action resembles that of antibiotics. In the latter case, the oxidative damage evoked by hydroxyl radicals has been suggested as a common mechanism for antibiotic-mediated cell death (Gutteridge et al., 1998; Kohanski et al., 2010).

\section{MATERIALS AND METHODS HONEYS}

Honeys were donated by beekeepers and included both commercial (pasteurized) and apiary (raw) samples. The list of honeys, their plant origin main physico-chemical characteristics is given in Table 1.

\section{BACTERIAL STRAINS}

Standard strains of B. subtilis (ATCC 6633) and E. coli (ATCC 14948) purchased from Thermo Fisher Scientific Remel Products (Lenexa, KS 66215, USA) were grown in Mueller-Hinton Broth (MHB; Difco Laboratories) overnight in a shaking water bath at $37^{\circ} \mathrm{C}$. Overnight cultures were diluted with broth to the equivalent of the $0.5 \mathrm{McF}$ arland Standard.

Clinical isolates were obtained from the Clinical Microbiology Laboratory of the London Health Science Centre, London, ON, Canada, three strains of vancomycin-resistant Enterococcus faecium and four strains of MRSA. On receipt these were subcultured from swabs onto Mueller-Hinton II agar (Difco Laboratories). Originally the organisms were isolated and processed at the Department of Clinical Microbiology of the London Health Science Centres. An automated system (Vitek ${ }^{\circledR}$, Biomérieux ${ }^{\circledR}$ ) was used to identify bacterial isolates to genus and species and their susceptibility to antibiotics (Table 2 and 3 ).

\section{IDENTIFICATION OF CLINICAL ISOLATES AND CONFIRMATION OF ANTIBIOTIC RESISTANCE}

Isolates were identified to genus and species and their susceptibility to antibiotics was confirmed using an automated system (Vitek ${ }^{\circledR}$, Biomérieux $\left.{ }^{\circledR}\right)$. The presence of the mec (A) gene, nuc gene, and van $(A)$ and $(B)$ genes were determined by polymerase chain reaction. 
Table 1 | List of honeys.

\begin{tabular}{|c|c|c|c|c|}
\hline Honey & Botanical source & Color $\left(A_{560-A 720}\right)$ & Hydrogen peroxide (mM/L)* & Water activity Aw \\
\hline Spl. 11 & Sweet clover (mix) Melilotus officinalis & 0.131 & $2.49 \pm 0.03$ & 0.550 \\
\hline Spl. 15 & Blueberry Vaccinium corymbosum & 0.267 & $1.75 \pm 0.02$ & 0.605 \\
\hline Spl. 58 & Buckwheat & 0.989 & $2.68 \pm 0.04$ & 0.576 \\
\hline Spl. 76 & Buckwheat & 0.906 & $2.56 \pm 0.06$ & 0.591 \\
\hline Spl. 103 & Buckwheat & 0.203 & $2.40 \pm 0.08$ & 0.601 \\
\hline Manuka & Leptospermum scoparium & 0.539 & $1.04 \pm 0.17$ & 0.617 \\
\hline $\mathrm{H} 203$ & Buckwheat & NA & $0.248 \pm 0.02$ & NA \\
\hline $\mathrm{H} 204$ & Buckwheat & NA & $0.744 \pm 0.01$ & NA \\
\hline H205 & Buckwheat & NA & $1.168 \pm 0.05$ & NA \\
\hline
\end{tabular}

*Hydrogen peroxide concentration was measured at honey dilution of $8 \times(25 \% \mathrm{v} / \mathrm{v})$ and represents an average of three experimental trials, where each honey was tested in triplicate

Table 2 | Susceptibility of clinical isolates to antibiotics.

\begin{tabular}{|c|c|c|c|c|c|c|c|c|c|c|c|c|c|c|c|c|c|c|c|c|}
\hline Bacterium & Antibiotics & & & & & & & & & & & & & & & & & & & \\
\hline MRSA 3 & + & & $\mathrm{R}$ & $\mathrm{R}$ & $\mathrm{R}$ & $\mathrm{R}$ & $\mathrm{R}$ & $S$ & & $\mathrm{R}$ & $\mathrm{S}$ & $\mathrm{R}$ & S & $\mathrm{R}$ & S & $S$ & & S & $S$ & $S$ \\
\hline MRSA 5 & + & & $\mathrm{R}$ & $\mathrm{R}$ & $\mathrm{R}$ & $\mathrm{R}$ & $\mathrm{R}$ & $\mathrm{R}$ & & $\mathrm{R}$ & $\mathrm{S}$ & I & $S$ & $\mathrm{R}$ & S & $S$ & & S & $S$ & $S$ \\
\hline VRE 0 & - & $\mathrm{R}$ & $\mathrm{R}$ & $\mathrm{R}$ & & $\mathrm{R}$ & $\mathrm{R}$ & & $S$ & $\mathrm{R}$ & $S$ & & $\mathrm{R}$ & & S & & $S$ & $\mathrm{R}$ & & $\mathrm{R}$ \\
\hline VRE 2 & - & $\mathrm{R}$ & $\mathrm{R}$ & $\mathrm{R}$ & & $\mathrm{R}$ & $\mathrm{R}$ & & $\mathrm{R}$ & $\mathrm{R}$ & $\mathrm{S}$ & & I & & S & & $\mathrm{R}$ & R & & $\mathrm{R}$ \\
\hline
\end{tabular}

1. Beta-lactamase; 2, ampicilli; 3, benzylpenicillin; 4, ciprofloxacin; 5, clindamycin; 6, erythromycin; 7, gatifloxacin; 8, gentamicin; 9, gentamicin high level (synergy); 10, levofloxacin; 11, linezolid; 12, moxifloxacin; 13, nitrofurantoin; 14, oxacillin; 15, quinupristin/dalfopristin; 16, rifampicin; 17, streptomycin high level (synergy); 18, tetracycline; 19, trimethoprim/sulfamethoxazole; 20, vancomycin.

Table 3 | Identification of clinical isolates and confirmation of antibiotic resistance.

\begin{tabular}{|c|c|c|c|c|c|c|}
\hline Plate & Identification & $\operatorname{mec}(A)$ & nuc & $\operatorname{van}(A)$ & $\operatorname{van}(B)$ & PB2 test \\
\hline VRE 0 & Vancomycin-resistant Enterococcus faecium & NA & NA & + & - & NA \\
\hline VRE 2 & Vancomycin-resistant Enterococcus faecium & NA & NA & + & - & NA \\
\hline VRE 3 & Vancomycin-resistant Enterococcus faecium & NA & NA & + & - & NA \\
\hline MRSA 3 & Methicillin-resistant Staphylococcus aureus & + & + & NA & NA & + \\
\hline MRSA 4 & Methicillin-resistant Staphylococcus aureus & + & + & NA & NA & + \\
\hline MRSA 5 & Methicillin-resistant Staphylococcus aureus & + & + & NA & NA & + \\
\hline MRSA 6 & Methicillin-resistant Staphylococcus aureus & + & + & NA & NA & \\
\hline
\end{tabular}

This work was conducted by the Clinical Microbiology Laboratory, London Health Sciences Centre, London, ON, Canada.

Reproducibility for each strain was determined at minimum two experiments and maximum three conducted in triplicate. MIC was determined by using a protocol as described in Methods according to the National Committee for Clinical Laboratory Standards (NCCLS, 1996).

The overnight cultures of each strain were diluted in MHB to obtain $10^{8} \mathrm{cfu} / \mathrm{ml}$ using a $0.5 \mathrm{McF}$ arland standard.

\section{POLYMERASE CHAIN REACTION}

The procedure for identification and confirmation for both MRSA and VRE were as follows: Nasal and perineal swabs were inoculated onto chromogenic media designed to identify possible MRSA and VRE isolates (Colorex VRE, Alere, Inc., London, ON, Canada; MRSASelect ${ }^{\mathrm{TM}}$, Bio-Rad Redmond, WA, USA). Colonies suspected of being MRSA or VRE were confirmed using PCR. For MRSA confirmation the organism was assayed for the presence of the mec $(A)$ gene and nuclease. Suspected VRE were assayed for 
the presence of van (A) and van (B) genes. Sequences used were: MecA1: TGGCTATCGTGTCACAATCG (20 bases)

MecA2: CTGGAACTTGTTGAGCAGAG (20 bases)

Nuc1: GCGATTGATGGTGATACGGTT ( 21 bases)

Nuc2: AGCCAAGCCTTGACGAACTAAAGC (24 bases)

VanA1: GGGAAAACGACAATTGC (17 bases)

VanA2: GTACAATGCGGCCGTTA (17 bases)

VanB1: ATGGGAAGCCGATAGTC (17 bases)

VanB2: GATTTCGTTCCTCGACC (17 bases)

PCR was run according to a standard protocol that is used routinely in clinical microbiology laboratories.

\section{ANTIBACTERIAL ASSAY}

The antibacterial activity of honeys was performed using a broth microdilution assay in sterile, 96-well microplates (Costar, Thermo Fisher Scientific, Canada) in compliance with requirements of NCCLS (1996). Wells in rows B to G contained $110 \mu$ l of inoculated broth $\left(10^{6} \mathrm{cfu} / \mathrm{ml}\right.$ final concentrations for each of microorganisms). Wells in row A were filled with $200 \mu \mathrm{l}$ of $50 \%$ solution of honey in sterile water and were inoculated with $20 \mu \mathrm{l}$ of $10^{7} \mathrm{cfu} / \mathrm{ml}$ of bacterial culture. Serial twofold dilutions of honey were prepared by mixing and transferring $110 \mu \mathrm{l}$ of honey with $110 \mu \mathrm{l}$ of inoculated broth from row $\mathrm{A}$ to row $\mathrm{H}$ of a microplate. Row $\mathrm{G}$ contained only inoculum and served as a positive control and row $\mathrm{H}$ contained sterile $\mathrm{MHB}$ and served as a blank. In a single experiment, each honey was tested in triplicate.

After overnight incubation of plates at $37^{\circ} \mathrm{C}$ in a shaking water bath, bacterial growth was measured at $A_{595} \mathrm{~nm}$ using the Synergy HT multidetection microplate reader (Synergy HT, Bio-Tek Instruments, Winooski, VT, USA).

The contribution of color of honeys to the absorption was corrected by subtracting the absorbance of wells before (zero time) and after overnight incubation.

Statistical analysis and dose-response curves were obtained using K4 software provided by Synergy HT, Bio-Tek Instruments, Winooski, VT, USA.

Conversion of honey dilutions to honey concentrations (\% v/v):

\begin{tabular}{lllllll}
\hline Dilutions & $\mathbf{2 x}$ & $\mathbf{4 x}$ & $\mathbf{8 x}$ & $\mathbf{1 6 x}$ & $\mathbf{3 2 x}$ & $\mathbf{6 4 x}$ \\
\hline Concentrations & $50 \%$ & $25 \%$ & $12.5 \%$ & $6.25 \%$ & $3.125 \%$ & $1.56 \%$
\end{tabular}

\section{DETERMINATION OF MICs}

The absorbance readings obtained from the dose-response curve were used to construct growth inhibition profiles (GIPs). The minimal inhibitory concentrations ( $\mathrm{MIC}_{90}$ ) were determined from the GIPs curves and represented the lowest concentration of the honeys that inhibited the bacterial growth by $90 \%$ as measured by the absorbance at $A_{595} \mathrm{~nm}$.

QC/QA controls: estimation of the MICs was conducted only then when control bacterial strains in microdilution assay (row G) show sufficient growth. For each bacterial strain, 3-6 MICs were established in independent experiments. The obtained median MICs were the same or differed by \pm one doubling concentration.

\section{HYDROXY-RADICALS MEASUREMENTS}

$3^{\prime}$-( $p$-Aminophenyl) fluorescein (APF; Invitrogen, Canada) was used for the detection of hydroxyl radicals produced by honeys. A broth microdilution assay in 96-well microplate format containing inoculum and twofold serially diluted honeys was adapted to assess both hydroxyl radicals generated and bacterial growth. To each well the APF solution was added to a final concentration of $10 \mu \mathrm{M}$ (in $50 \mathrm{mM}$ potassium phosphate buffer, $\mathrm{pH}$ 7.4). The experimental wells (containing bacterial inoculum and honey dilutions) as well as the assay controls (bacterial inoculum) were supplemented with $10 \mu \mathrm{M}$ APF while the negative control consisted of experimental wells without APF.

Plates were incubated in a shaking water bath at $37^{\circ} \mathrm{C}$ for $18 \mathrm{~h}$. The plates were analyzed for both, bacterial growth using absorbance at $A_{595} \mathrm{~nm}$ and hydroxyl radical generation using fluorescence excitation and emission wavelengths at 490 and $520 \mathrm{~nm}$, respectively.

To measure hydroxyl radical generation in the presence of $\mathrm{Cu}$ ions, honeys were incubated with $400 \mu \mathrm{M}$ of $\mathrm{CuCl}_{2}$ dissolved in $50 \mathrm{mM}$ potassium phosphate buffer, $\mathrm{pH}$ 7.4.

\section{HYDROGEN PEROXIDE ASSAY}

The hydrogen peroxide concentrations of the honeys were determined using the Amplex Red Hydrogen Peroxide/Peroxidase Assay Kit in 96-well microplate format according to the manufacturer manual (Molecular Probes, Invitrogen, Burlington, ON, Canada) and as described previously (Brudzynski et al., 2011). The Synergy HT multidetection microplate reader was used to measure the fluorescence formed during the reaction of honey's hydrogen peroxide with the Amplex Red reagent (10-acetyl-3,7dihydroxyphenoxasine). The measurements were conducted at an emission wavelength of $590 \mathrm{~nm}$, and an excitation wavelength of $530 \mathrm{~nm}$. The standard curve constructed from the known concentration of $\mathrm{H}_{2} \mathrm{O}_{2}$ was used to calculate the hydrogen peroxide concentrations of the honeys. Each of the honey samples, and the standard curve, were tested in triplicate.

\section{CATALASE-TREATMENT OF HONEYS}

Honey were treated with catalase (13 $800 \mathrm{U} / \mathrm{mg}$ solid; SigmaAldrich, Canada) at ratio of 1000 units per $1 \mathrm{ml}$ of $50 \%$ honey solution in sterile water for $2 \mathrm{~h}$ at room temperature.

\section{RESULTS \\ BACTERIOSTATIC EFFECT OF HONEY AGAINST ANTIBIOTIC-RESISTANT CLINICAL ISOLATES}

From a large pool of over 200 honeys screened for their bacteriostatic activity against $E$. coli and B. subtilis (Brudzynski and Kim, 2011), we selected eleven honeys that showed MIC 90 exceeding those of sugar solution (artificial honey). The list included six buckwheat honeys (H23, 58, 76, 77, 81, and 103), one clover honey (H11) and one blueberry honey (H15). The MIC90 of these honeys ranged from 6.25 to $12.5 \%$ (v/v), with exception of H15, with $\mathrm{MIC}_{90}$ of $25 \%(\mathrm{v} / \mathrm{v})$. New Zealand Active Manuka honey (MIC 90 $6.25 \% \mathrm{v} / \mathrm{v}$ ) was used as a reference (Figure 1 ).

These honeys were analyzed for their ability to inhibit growth of two vancomycin-resistant Enterococcus faecium, VRE 0 and VRE 2 and three strains of MRSA, MRSA 3, 4, and 5. Figure 1 shows 


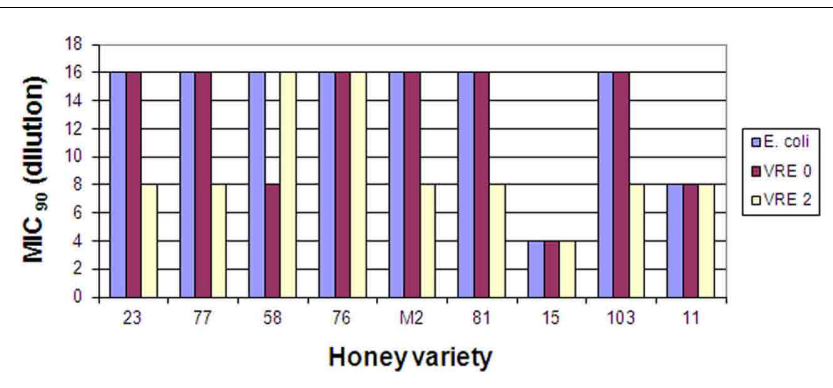

FIGURE 1 | Bacteriostatic activity of eleven honey varieties against two clinical isolates of vancomycin-resistant Enterococcus faecium strains, VRE $\mathbf{0}$ and VRE 2. Reproducibility for each strain was determined at minimum in three separate experiments conducted in triplicate.

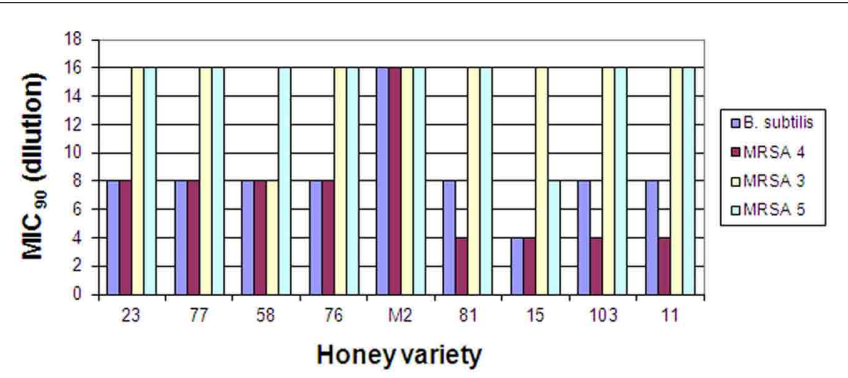

FIGURE 2 | Bacteriostatic activity of eleven honey varieties against two clinical isolates of methicillin-resistant Staphylococcus aureus strains, MRSA 3, 4, and 5. Reproducibility for each strain was determined at minimum in three separate experiments conducted in triplicate.

that both VRE strains were susceptible to honeys. The median differences in honeys bacteriostatic activity varied only by twofold from the low MIC to the high MIC for each strains (MIC 90 6.25 and $12.5 \%$ (v/v), respectively), with exception of honey $\mathrm{H} 15$. Both VRE strains displayed the same multi-drug resistant pattern (Table 2). There was no difference in MIC values of honeys against multi-drug resistant VRE strains and E. coli (Figure 1).

On the other hand, the susceptibility of the three strains of MRSA to honeys differed two- to four-fold ranging from $\mathrm{MIC}_{90}$ $6.25-25 \%(\mathrm{v} / \mathrm{v})$. MRSA 4 was the most resistant strain while MRSA 3 and 5 were more susceptible to different honeys. MRSA 4 was more resistant to honey action than B. subtilis (Figure 2).

The antibiograms performed on MRSA and VRE strains showed similar multi-resistance profiles to several classes of antibiotics (Table 2).

\section{CONFIRMATION OF THE PRESENCE OF RESISTANCE GENES IN CLINICAL ISOLATES}

These pathogens isolated from wounds were identified to the genus and species using the automated system Vitek II, Biomerieux. The presence or absence of antibiotic resistance genes [ $\operatorname{van}(A)$, $\operatorname{van}(B), \operatorname{mec}(A)$, and $n u c]$ was confirmed by the polymerase chain reaction. The presence of penicillin-binding protein $\left(\mathrm{PBP}^{\prime}\right)$ in the Staphylococcus aureus strains were confirmed using an Oxoid agglutination kit.
Despite the multi-resistance pattern to antibiotics (Table 2), supported by a positive identification of the antibiotic-resistant genes (Table 3), all strains of MRSA and VRE were sensitive to honey bacteriostatic action (Figures 1 and 2). This observation together with the lack of significant differences in susceptibility between the antibiotic-resistant and standard bacteria suggested that bacteriostatic action of honey may proceeds via a common mechanism.

\section{DETECTION OF HYDROXYL RADICAL FORMATION FOLLOWING INCUBATION OF MRSA AND VRE WITH HONEYS}

In our most recent study, we have shown that hydrogen peroxide is implicated in bacterial growth inhibition but its inhibitory efficiency was modulated by unknown honey components (Brudzynski et al., 2011). We hypothesized that the formation of $\bullet^{\bullet} \mathrm{OH}$ from $\mathrm{H}_{2} \mathrm{O}_{2}$ rather than $\mathrm{H}_{2} \mathrm{O}_{2}$ itself may be directly implicated in bacterial growth inhibition.

To investigate the generation of $\bullet \mathrm{OH}$ from honey's hydrogen peroxide and its effect on bacterial growth, we exposed MRSA and VRE culture to serially diluted honeys in the presence of $3^{\prime}$-( $p$-aminophenyl) fluorescein $(\mathrm{APF})$ as $\bullet \mathrm{OH}$ trap (Setsukinai et al., 2003). APF is a non-fluorescent product but in the presence of ${ }^{\bullet} \mathrm{OH}$ it became oxidized to a fluorescent form. It has been shown that, the ${ }^{\bullet} \mathrm{OH}$ trapping by APF resulted in a dose-dependent increase in the fluorescence (Setsukinai et al., 2003).

Using broth microdilution assay supplemented with APF, we analyzed in the same experiment the growth of MRSA and VRE by monitoring the increase in turbidity/absorbance at $A_{595} \mathrm{~nm}$ and the generation of hydroxyl radicals by monitoring the increase in fluorescence.

Two new bacterial strains, MRSA 6 and VRE 3 were exposed separately to five freshly obtained buckwheat honeys: H203, 204, 205, and 206. The incubation of each honey with MRSA 6 and VRE 3 cultures resulted with steady accumulation of hydroxyl radicals up to the $16 \times$ honey dilution, as assessed by increase in fluorescence (Figures 3A,B). The peak of ${ }^{\bullet} \mathrm{OH}$ generation corresponded to the MIC of honey. Further honey dilutions resulted in a decrease of - OH levels and concomitant loss of growth inhibition. Thus, there was a causal relationship between ${ }^{\bullet} \mathrm{OH}$ generation and bacterial growth inhibition.

No major differences were observed in the growth inhibition patterns between the six honeys; neither in the final MIC values against MRSA 6 and VRE 3 nor in the levels of ${ }^{\bullet} \mathrm{OH}$ generation during incubations. Therefore, Figures $\mathbf{3 A}, \mathbf{B}$ represent an average from the all honeys used against VRE (Figure 3A) and against MRSA (Figure 3B).

The relationship between honey dilutions and hydroxyl radical production was strongly reminiscent of that between honey dilutions and hydrogen peroxide production (Brudzynski et al., 2011). Previous studies have established that honey dilutions facilitate the production of endogenous $\mathrm{H}_{2} \mathrm{O}_{2}$ by glucose oxidase (White et al., 1963; Bang et al., 2003; Brudzynski et al., 2011). In most of our test honeys, a steady increase in $\mathrm{H}_{2} \mathrm{O}_{2}$ content with honey dilution was observed, reaching the peak of production between $4 \times$ and $16 \times$ dilution and declining thereafter (Brudzynski et al., 2011).

When the results on ${ }^{\circ} \mathrm{OH}$ generation during incubation of honeys with MRSA and VRE were combined and presented 

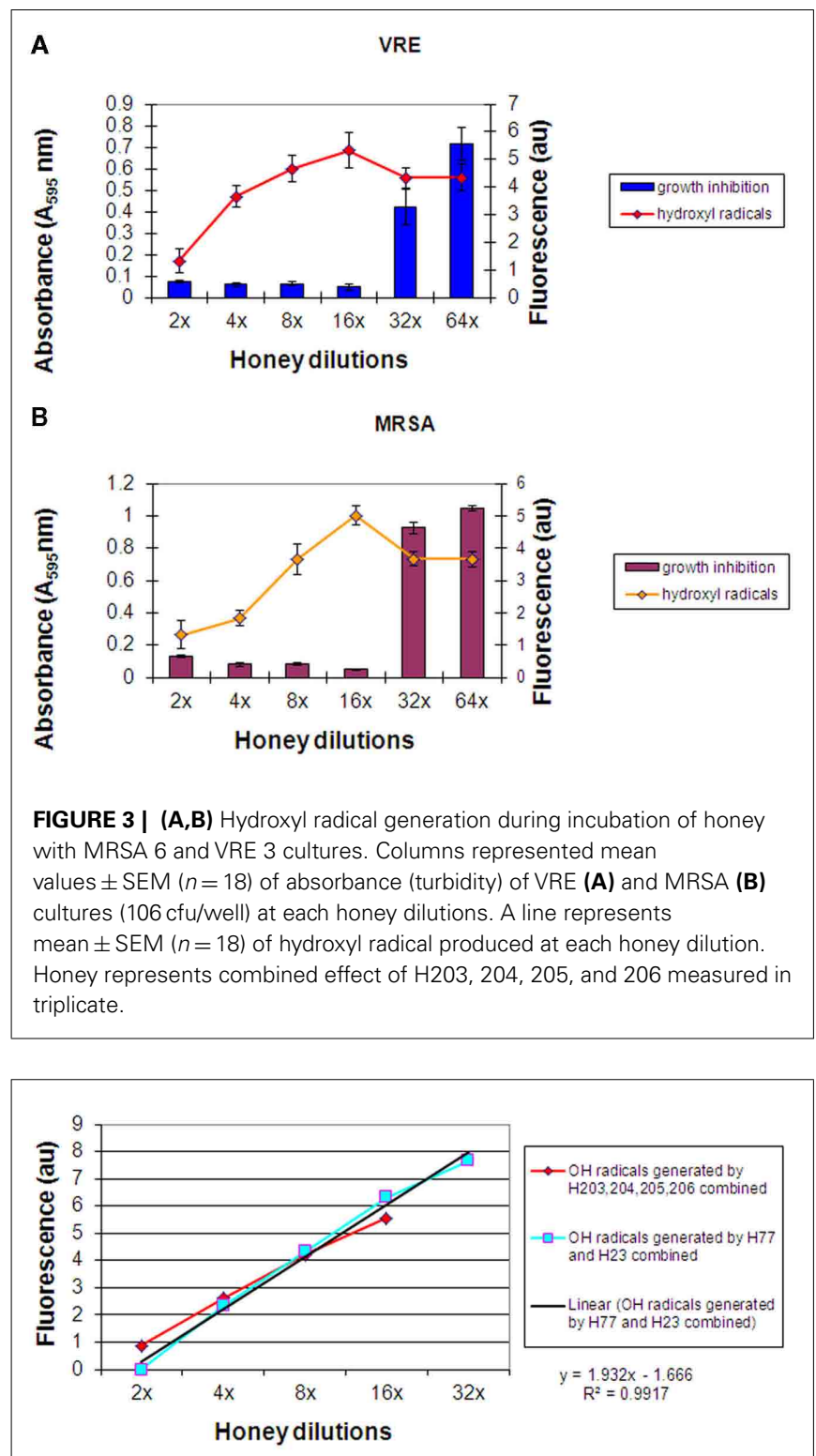

FIGURE 4 | Linear relationship between honey dilutions and hydroxyl radical generation from honey's hydrogen peroxide.

graphically, it appeared that there was a linear relation between the increase in ${ }^{\bullet} \mathrm{OH}$ concentrations and honey dilution. Figure 4 shows the linearity up to 16-fold dilution in case of H203-206 (median $\mathrm{H}_{2} \mathrm{O}_{2}$ content of $0.8 \mathrm{mM}$ ) and 32-fold dilution for honeys $\mathrm{H} 77$ and $\mathrm{H} 76$ (median $\mathrm{H}_{2} \mathrm{O}_{2}$ content of $2.63 \mathrm{mM}$, Table 1). This finding suggested that honey dilutions, the increased production of $\mathrm{H}_{2} \mathrm{O}_{2}$, and increased generation of ${ }^{\bullet} \mathrm{OH}$ are interdependent phenomena.

\section{EFFECT OF CU IONS AND CATALASE ON THE HYDROXYL RADICAL PRODUCTION AND HONEY BACTERIOSTATIC ACTIVITY}

Hydroxyl radicals are generated as a result of the coupling chemistry between hydrogen peroxide and metal ions $\mathrm{Fe}$ (II) or $\mathrm{Cu}$ (II) via Fenton reaction. To test whether the Fenton reaction is

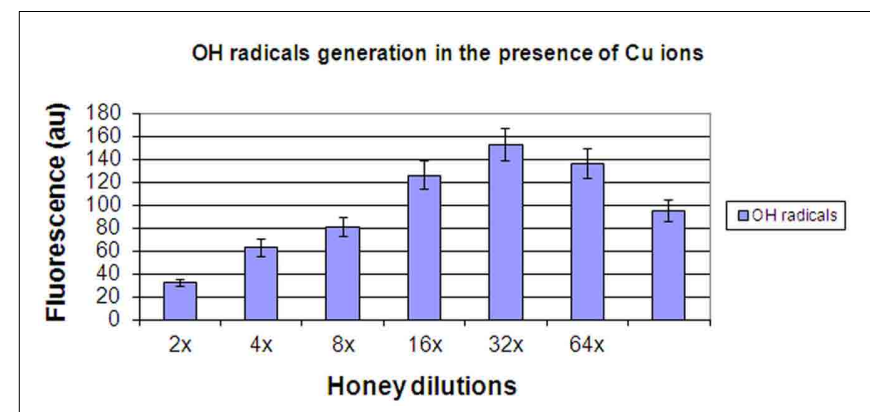

FIGURE 5 |The generation of hydroxyl radicals by honeys $\mathrm{H77}$ and $\mathrm{H76}$ (combined) supplemented with $400 \mu \mathrm{M} \mathrm{Cu}$ (II).

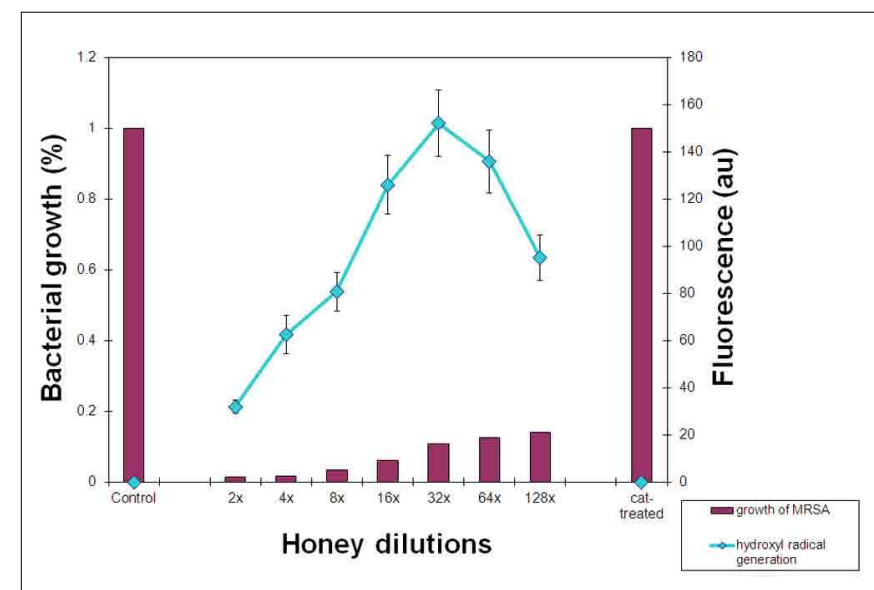

FIGURE 6 | Relationship between hydroxyl radical generation and inhibition of MRSA cultures by honeys $\mathrm{H77}$ and $\mathrm{H76}$ supplemented with $\mathbf{C u}$ ions. Columns represent growth of MRSA expressed as a percentage of control (growth of MRSA in the absence of honey, 100\%) exposed to the serially diluted honey. A line represents fluorescence of hydroxyl radicals trapped by APF during incubation of honeys with MRSA. Cat-treated sample represents growth of MRSA in the presence of honey pre-treated with catalase and then supplemented with $\mathrm{Cu}$ ions.

responsible for ${ }^{\bullet} \mathrm{OH}$ production from endogenous $\mathrm{H}_{2} \mathrm{O}_{2}$, we supplemented honeys with $\mathrm{Cu}$ ions $(400 \mu \mathrm{M})$ and incubated with MRSA cells in broth microdilution assay.

The results confirmed that upon addition of $\mathrm{Cu}$ ions to honeys the generation of $\bullet \mathrm{OH}$ radicals from $\mathrm{H}_{2} \mathrm{O}_{2}$ was substantially enhanced (Figure 5). Approximately 30 -fold higher level of $\bullet$ was observed in the presence of $\mathrm{Cu}$ ions compared to control honeys. Similarly to results presented in Figure 4 , a curve of $\bullet$ radical generated under these conditions was essentially linear up to 32-fold dilution. These data indicate that $\mathrm{Cu}$ ions facilitated decomposition of $\mathrm{H}_{2} \mathrm{O}_{2}$ to generate $\bullet \mathrm{OH}$, as expected from the classical Fenton reaction.

The increased levels of $\mathrm{H}_{2} \mathrm{O}_{2}$ decomposition and hydroxyl radical generation in the presence of $\mathrm{Cu}$ ions dramatically augmented honey bacteriostatic potency. When honeys H77 and H76 supplemented with $\mathrm{Cu}$ ions were incubated with MRSA 6 cells, the bacterial growth was inhibited beyond 128-fold honey dilution, increasing honey $\mathrm{MIC}<0.78 \% \mathrm{v} / \mathrm{v}$ (Figure 6). The direct 
connection between the increase in ${ }^{\bullet} \mathrm{OH}$ generation and the increase in growth inhibition of MRSA by honey supplemented with $\mathrm{Cu}$ is consistent with the conclusion that hydroxyl radicals are primarily responsible for this cytotoxic effect.

To demonstrate that honey $\mathrm{H}_{2} \mathrm{O}_{2}$ is a substrate in the generation of hydroxyl radicals in these experiments, we first pre-treated honeys $\mathrm{H} 77$ and $\mathrm{H} 76$ with catalase to remove $\mathrm{H}_{2} \mathrm{O}_{2}$ and then supplemented them with $\mathrm{Cu}$ ions. Addition of catalase completely abolished inhibitory action of honey and bacterial growth was fully restored. In the same time, the ${ }^{\bullet} \mathrm{OH}$ generation was reduced to 0 in catalase-treated honeys (Figure 6).

Together, these results indicate that ${ }^{\bullet} \mathrm{OH}$ radicals were generated from the honey endogenous $\mathrm{H}_{2} \mathrm{O}_{2}$ via the Fenton reaction. The $\bullet \mathrm{OH}$ radical exerted dose-dependent inhibitory effect on MRSA and VRE growth.

\section{DISCUSSION}

In this study, the $3^{\prime}$-( $p$-Aminophenyl) fluorescein (APF) ${ }^{\bullet} \mathrm{OH}$ trap technique was used to provide direct evidence that hydroxyl radical generation from honey hydrogen peroxide caused inhibition of growth of multi-drug resistant clinical isolates of MRSA and VRE, as well as growth of standard bacteria, E. coli and B. subtilis. Application of APF allowed us to measure simultaneously (in the same experiment) the generation of hydroxyl radicals and their effects on growth of MRSA and VRE cells.

Firstly, we have established that the antibiotic-resistant clinical isolates, VRE 0 and VRE 2, carrying vancomycin-resistance genes $\operatorname{van}(A)$ and MRSA 3, 4, and 5 carrying $\operatorname{mec}(A)$ and PBP2' genes, all were sensitive to honey actions. The variability in honeys median MICs against MRSA and VRE were comparable to those against E. coli and B. subtilis and ranged from 6.25 to $12.5 \%$ v/v. Similar results have been previously obtained for honeys of Leptospermum origin, (manuka; Willix et al., 1992; Cooper et al., 2000, 2002a,b; French et al., 2005; Blair et al., 2009), K. excelsa (tualang; Tan et al., 2009), and F. esculentum (buckwheat; Brudzynski and Lannigan, 2008).

The presence of several antibiotic resistance genes therefore, did not interfere with the honey action against these microorganisms, providing an important clue that the underlying mechanism may concern a common biochemical pathway affecting all bacteria. The observed slight variability in susceptibility of different MRSA to honey may be a reflection of their ability to counteract the oxidative stress.

Secondly, exposure of MRSA and VRE to tested honeys resulted in a steady accumulation of hydroxyl radicals, as evidenced by increased fluorescence of APF, reaching the peak between 16and 32-fold honey dilution. The dilution of honey at which the maximal $\bullet \mathrm{OH}$ generation was observed corresponded to honey MIC. After reaching this culmination point, both hydroxyl radical generation and growth inhibition showed a decline, indicating a functional interplay between these two events.

The relationship between generation of $\bullet \mathrm{OH}$ and the extent of growth inhibition strongly resembled the relationship between the production of $\mathrm{H}_{2} \mathrm{O}_{2}$ upon honey dilution and inhibition of bacterial growth (Brudzynski et al., 2011). This observation implied that honey $\mathrm{H}_{2} \mathrm{O}_{2}$ might be a main source of $\bullet \mathrm{OH}^{\circ}$ radicals. A generally accepted mechanism of ${ }^{\bullet} \mathrm{OH}$ generation is the Fenton reaction in which $\mathrm{H}_{2} \mathrm{O}_{2}$ is reduced to ${ }^{\bullet} \mathrm{OH}$ in the presence of transition metal ions (Puppo, 1992; Hanasaki et al., 1994; Cao et al., 1997; Urbanski and Beręsewicz, 2000). Honey is naturally enriched in transition metals such as $\mathrm{Fe}(\mathrm{II})$ or $\mathrm{Cu}$ (II) (Bogdanov et al., 2007) and produces its own $\mathrm{H}_{2} \mathrm{O}_{2}$, thus fulfilling requirements for the Fenton -type reaction to occur. Consistently with this premise, supplementation of honey with $\mathrm{Cu}(\mathrm{II})$ caused a remarkable increase in - $\mathrm{OH}$ production. This increase was completely abolished by pretreatment of honey with catalase prior to addition of $\mathrm{Cu}$ ions, clearly indicating that honey $\mathrm{H}_{2} \mathrm{O}_{2}$ was a source from which of - $\mathrm{OH}$ radicals were generated. A coupling chemistry via the Fenton reaction is then the most plausible mechanism operating in honey since, similarly to results observed here, removal of $\mathrm{H}_{2} \mathrm{O}_{2}$ or chelation of metal ions prevented hydroxyl radical generation in Fenton reaction (Puppo, 1992; Ali and Konishi, 1998; Urbanski and Beręsewicz, 2000).

Furthermore, a tight functional relationship was observed between levels of hydroxyl radicals produced and honey bacteriostatic potency. We observed that MICs of honeys increased from $6.25 \% \mathrm{v} / \mathrm{v}$ to less than $0.78 \% \mathrm{v} / \mathrm{v}$ (below 128 -fold dilution) after $\mathrm{Cu}$-supplementation. Again, this augmented bacteriostatic activity was catalase-sensitive: removal of $\mathrm{H}_{2} \mathrm{O}_{2}$, which in turn abolished - OH generation, resulted in the full restoration of bacterial growth.

These results indicate that the oxidative stress caused by honey action on bacterial cells resulted from hydroxyl radical generated from honey's hydrogen peroxide rather than from the action of molecular $\mathrm{H}_{2} \mathrm{O}_{2}$ itself. The formed hydroxyl radicals inhibited the growth of MRSA and VRE in a dose-dependent manner. Thus, we established here a functional link between the generation of hydroxyl radicals from honey $\mathrm{H}_{2} \mathrm{O}_{2}$ and bacterial growth inhibition.

There is a tremendous need for novel antibacterial agents to treat infections caused by antibiotic-resistant bacteria. Honey, with its long history of usage as an antibacterial agent in traditional and folk medicine (for review, Lusby et al., 2002), has recently brought renewed attention of researchers working in the area of drug discovery and development. Accumulated evidence from basic research and clinical trials allowed manuka honey (derived from Leptospermum species) to be recognized as a therapeutic agent. Its antibacterial effectiveness in wound healing has been documented in many case studies and randomized controlled trials (for review, Molan, 2006). As the result, at least two types of formulations based on manuka honey, Medihoney ${ }^{\mathrm{TM}}$ and Active Honey Absorbent Dressing, API-MED ${ }^{\mathrm{TM}}$ have been approved to be used in clinical treatments of infected wounds.

One of the principle limitations of many antibacterial agents derived from natural products, including honey, is lack of knowledge about a molecular mechanism that lead to bacterial cell death. In this context, our finding that hydroxyl radicals generated by honeys (other than manuka honey) underlie its antibacterial activity may be critical for designing effective antibacterial therapy for the following reasons: (a) generation of hydroxyl radical is a common property of honeys of European and North American origin, (b) the hydroxyl radical-based mechanism of honey action did not discriminate between antibiotic-sensitive and antibiotic-resistant bacteria, and (c) hydroxyl radical levels generated by honey could serve as a diagnostic tool to predicted antibacterial efficacy of honeys in clinical applications. 


\section{ACKNOWLEDGMENTS}

The authors would like to thank Heitham Qubaja for technical assistance. This research was supported by funds

\section{REFERENCES}

Ali, M. A., and Konishi, T. (1998). Enhancement of hydroxyl radical generation in the Fenton reaction by alpha-hydroxy acid. Biochem. Mol. Biol. Int. 46 137-145.

Bang, L. M., Buntting, C., and Molan, P. (2003). The effect of dilution on the rate of hydrogen peroxide production in honey, and its implications for wound healing. J. Altern. Complement. Med. 9, 267-273.

Blair, S. E., Cokcetin, N. N., Harry, E. J., and Carter, D. A. (2009). The unusual antibacterial activity of medical-grade Leptospermum honey: antibacterial spectrum, resistance and transcriptome analysis. Eur. J. Clin. Microbiol. Infect. Dis. 28, 1199-1208.

Bogdanov, S., Haldimann, M., Luginbühl, W., and Gallmann, P. (2007). Minerals in honey; environmental, geographical and botanical aspects. J. Apic. Res. Bee World 46, 269-275

Brudzynski, K. (2006). Effect of hydrogen peroxide on antibacterial activities of Canadian honeys. Can. J. Microbiol. 52, 1228-1237.

Brudzynski, K., Abubaker, K., and Miotto, D. (2012). Unraveling a mechanism of honey antibacterial action: polyphenol/ $\mathrm{H} 2 \mathrm{O} 2$ -induced oxidative effect on bacterial cell growth and on DNA degradation. Food Chem. doi: 10.1016/i.foodchem.2012.01.035

Brudzynski, K., Abubaker, K, St. Martin, L., and Castle, A. (2011). Re-examining the role of hydrogen peroxide in bacteriostatic and bactericidal activities of honey. Front. Microbiol. 2:213. doi:10.3389/fmicb.2011.00213

Brudzynski, K., and Kim, L. (2011). Storage-induced chemical changes in active components of honey deregulate its antibacterial activity. Food Chem. 126, 1155-1163.

Brudzynski, K., and Lannigan, R. (2008). Evaluation of efficacy of Canadian honeys against woundinfecting bacteria in vitro. Wound Care 6, 54

Brudzynski, K., and Miotto, D. (2011). The relationship between the content of Maillard-reaction-like products and bioactivity of Canadian honeys. Food Chem. 124, 867-874.

Cao, G., Sofic, E., and Prior, R. L. (1997). Antioxidant and prooxidant behaviour of flavonoids: structure-activity relationships. Free Radic. Biol. Med. 22, 749-760.

Cooper, R. A., Molan, P. C., and Harding, K. G. (2002a). The sensitivity to honey of Gram-positive cocci of clinical significance isolated from wounds. J. Appl. Microbiol. 93, 857-863.

Cooper, R. A., Halas, E., and Molan, P. C. (2002b). The efficacy of honey in inhibiting strains of Pseudomonas aeruginosa from infected burns. J. Burn Care Rehabil. 23, 366-370.

Cooper, R. A., Wigley, P., and Burton, N. F. (2000). Susceptibility of multiresistant strains of Burkholderia cepacia to honey. Lett. Appl. Microbiol. 31, 20-24.

Finnegan, M., Linley, E., Denyer, S. P., McDonnell, G., Simon, C., and Maillard, J.-Y. (2010). Mode of action of hydrogen peroxide and other oxidizing agents: differences between liquid and gas forms. J. Antimicrob. Chemother. 65, 2108-2115.

French, V. M., Cooper, R. A., and Molan, P. C. (2005). The antibacterial activity of honey against coagulase-negative staphylococci. J. Antimicrob. Chemother. 56, 228-231.

Gutteridge, J. M., Quinlan, G. J., and Kovacic, P. (1998). Phagomimetic action of antimicrobial agents. Free Radic. Res. 28, 1-14.

Halliwell, B., Gutteridge, J. M. C., and Blake, D. (1985). Metal ions and oxygen radical reactions in human inflammatory joint disease. Philos. Trans. R. Soc. Lond. B Biol. Sci. 311, 659-671.

Hanasaki, Y., Ogawa, S., and Fukui, S. (1994). The correlation between active oxygen scavenging and antioxidant effects of flavonoids. Free Radic. Biol. Med. 16, 845-850.

Imlay, J. A., Chin, S. M., and Linn, S. (1988). Toxic DNA damage by hydrogen peroxide through the Fenton reaction in vivo and in vitro. Science 240, 640-642.

Imlay, J. A., and Linn, S. (1988). DNA damage and oxygen radical toxicity. Science 240, 1302-1309.

Irish, J., Blair, S., and Carter, D. A. (2011). The antibacterial activity of honey derived from Australian flora. PLoS ONE 6, el8229. doi:10.1371/journal.pone.0018229

from the Agricultural Adaptation Council, Agriculture and Agri-Food Canada, and the Ontario Centres of Excellence.

Kohanski, M. A., Dwyer, D. J., and Collins, J. J. (2010). How antibiotics kill bacteria: from target to networks. Nat. Rev. Microbiol. 8 423-435.

Lusby, P. E., Combes, A. L., and Wilkinson, J. M. (2002). Honey-a potential agent for wound healing? JWOCN 29, 296-300.

Majtan, J., Majtanova, L., and Majtan, V. (2010). Honeydew honey as a potent antibacterial agent in eradication of multi-drug resistant Stenotrophomonas maltophilia isolates from cancer patients. Phytother. Res. 25, 584-587.

Molan, P. (2006). The evidence supporting the use of honey as a wound dressing. Int. J. Low. Extrem. Wounds 5, 40-50.

NCCLS. (1996). "Susceptibility testing of antibiotics in liquid media," in Antibiotics in Laboratory Medicine, 4th Edn, ed. V. Lorian (Baltimore, MD: Williams and Wilkins), 52-111.

Perrone, G. G., Tan, S.-X., and Dawes, I. W. (2008). Reactive oxygen species and yeast apoptosis. Biochim. Biophys. Acta 1783, 1354-1368.

Price, J. A., Sanny, C. G., and Shevlin, D. (2006). Application of manual assessment of oxygen radical absorbent capacity (ORAC) for use in high throughput assay of "total" antioxidant activity of drugs and natural products. J. Pharmacol. Toxicol. Methods 54, 56-67.

Puppo, A. (1992). Effect of flavonoids on hydroxyl radical formation by Fenton-type reactions; influence of the iron chelator. Phytochemistry 31, 85-88.

Rutala, W. A., Weber, J. D, and The Healthcare Infection Control Practices Advisory Committee. (2008). Guideline for Disinfection and Sterilization in Healthcare Facilities. Centers for Disease Control and Prevention (CDC), Departmentof Health and Human Services USA, Chapel Hill.

Sakihama, Y., Cohen, M. F., and Grace, S. C. Yamasaki, H. (2002). Plant phenolic antioxidant and prooxidant activities: phenolics-induced oxidative damage mediated by metals in plants. Toxicology 177, 67-80.

Setsukinai, K., Urano, Y., Kakinuma, K., Majima, H. J., and Nagano, T. (2003). Development of novel fluorescence probes that can reliably detect reactive oxygen species and distinguish specific species. J. Biol. Chem. 278, 3170-3175.

Tan, H. T., Rahman, R. A., Gan, S. H., Halim, A. S., Hassan, S. A., Sulaiman, S. A., and Kirnpal-Kaul, B. S. (2009). The antibacterial properties of Malaysian tualang honey against wound and enteric microorganisms in comparison to manuka honey. BMC Complement. Altern. Med. 9, 34. doi:10.1186/1472-6882-9-34

Urbanski, N. K., and Beręsewicz, A. (2000). Generation of $\mathrm{OH}$ intiated by interaction of $\mathrm{Fe} 2+$ and $\mathrm{Cu}+$ with dioxygen; comparison with the Fenton chemistry. Acta Biochim. Pol. 47, 951-962.

White, J. W., Subers, M. H., and Schepartz, A. I. (1963). The identification of inhibine, the antibacterial factor in honey, as hydrogen peroxide, and its origin in a honey glucose-oxidase system. Biochem. Biophys. Acta 73, 57-70.

Willix, D. J., Molan, P. C., and Harfoot, C. G. (1992). A comparison of the sensitivity of wound-infecting species of bacteria to the antibacterial activity of manuka honey and other honey. J. Appl. Bacteriol. 73, 388-394.

Conflict of Interest Statement: The authors declare that the research was conducted in the absence of any commercial or financial relationships that could be construed as a potential conflict of interest.

Received: 23 November 2011; accepted: 23 January 2012; published online: 07 February 2012.

Citation: Brudzynski $K$ and Lannigan $R$ (2012) Mechanism of honey bacteriostatic action against MRSA and VRE involves hydroxyl radicals generated from honey's hydrogen peroxide. Front. Microbio. 3:36. doi: 10.3389/fmicb.2012.00036 This article was submitted to Frontiers in Antimicrobials, Resistance and Chemotherapy, a specialty of Frontiers in Microbiology.

Copyright (c) 2012 Brudzynski and Lannigan. This is an open-access article distributed under the terms of the Creative Commons Attribution Non Commercial License, which permits noncommercial use, distribution, and reproduction in other forums, provided the original authors and source are credited. 